\title{
Tracing Giftedness: An Exploration of Theories, Programmes and Emerging Dilemmas
}

\author{
Anupama Mahajan*
}

\begin{abstract}
In the recent years, the conception of giftedness in children has garnered a lot of attention from educationists and psychologists in India. Children marked as gifted are said to display above average abilities as compared with their peers. In this paper, I attempt to show that despite multiple notions and theories of giftedness, displaying exceptional abilities in mathematics and science seem to be the dominant focus and trend. In support of this claim, I list out the various Gifted and Talented Programmes of Giftedness in India. By exploring the various landscapes of excellence across diverse schooling environment, I draw from my doctoral research to highlight the ways in which giftedness is socially circulating and the factors that produce, and the processes that enable and sustain it.

Through this study, I hope to contribute to the sociology of education in terms of understanding middle class / elite aspirations with regard to education of their children, elite parenting practices, conceptions of giftedness and how 'cultural capital' is transmitted from one generation to the next.
\end{abstract}

Keywords: Gifted Children, Gifted and Talented Programmes, Academic Giftedness, Conceptions of Giftedness, Construction of Ability, Parental Aspirations

\footnotetext{
* National Institute of Advanced Studies, Bengaluru, India; anabi21@gmail.com
} 


\section{Introduction}

In recent years, the concept of giftedness in children has received a lot of attention in the field of Education, Psychology and Sociology. Great interest is shown in children who display above average abilities, compared to their peers, and are identified as 'gifted'. In this report, I attempt to unpack the notion of giftedness as understood through various models, discourses and talent programmes, to find that in spite of the multiplicity in approaches to giftedness, emphasis on the STEM disciplines and children excelling in Math or Science appears to be the dominant understanding. Through my doctoral research on gifted children in diverse schooling environments, I explore the implications of this dominant understanding on children and their personhood, and look at certain dilemmas that it engenders in the homes, schools and other enrichment spaces that they inhabit.

\section{Identifying gifted children: Theories and processes}

There are several different and contrasting definitions of giftedness which have been given by Paul Witty ${ }^{i}$, Joseph Renzulliii, Howard Gardneriii, Robert Sternbergiv and The Columbus Groupv. In defining giftedness, despite differences, psychological perspectives have been dominant and several models and theories have been formulated and applied to the lives of children. For example, Joseph Renzulli's Three-Ring Model considers above average ability, creativity and task commitment as the parameters for gifted behaviour. Robert Sternberg's theory of Successful Intelligence highlights "the ability to adapt to, shape, and select environments to accomplish one's goals and those of one's society and culture" (Sternberg, 1997 as cited in Reynolds \& Miller, 2013, p. 35). The Dynamic theory of giftedness by Lev Vygotsky emphasises social aspects of an individual's experience as playing an important role in the development of giftedness. Even with attempts to formulate notions of giftedness as a social phenomenon, which is a departure from the populist understanding of building scholastic ability, the term giftedness and intelligence was still closely associated with accomplishment of academic excellence. Howard Gardner's theory of Multiple Intelligences marked a departure. It was a sincere attempt at expanding the idea of intelligence to acknowledge the 
other equally important aspects of human cognitive capacities (Gardner, 2006). Despite having such a rich array of theories on giftedness that allow for different understandings in non-academic domains such as visual arts (Clark and Zimmerman, 1992 as cited in Callahan, C.M., 1997), music and sports (Bloom et al., 1985 as cited in Callahan, C.M., 1997), the dominant and societally endorsed notions of giftedness still retain their authority in disciplines such as mathematics and science. A glance at gifted and talented programmes in India will serve as an evidence for this claim.

\section{Tracing giftedness programmes in India: Nurturing talent, and beyond}

Giftedness as an idea is novel in India. Notions of giftedness and the need to provide educational resources to support gifted children are largely restricted to a few elite urban schools. However, one could argue that through education policies that have sought to "engage with talent" and "nurture young minds", notions of giftedness in children have a long history in India. Tracing these gifted programmes historically can help understand the pathways through which giftedness has found character and identity in the Indian context. I will briefly list out these programmes below.

One of the first attempts to understand the concept of giftedness was made by the Jagadis Bose National Science Talent Search (JBNSTS) vi. The JBNSTS is in the process of developing a STEM (Science, Technology, Engineering and Mathematics) curriculum which is an attempt made in the education of gifted and talented students (The Times of India, 2014). Additionally, the National Talent Search, Math and Science Olympiads, the Kishor Vigyanik Prothsahan Yojna competitions (Kurup, \& Maithreyi, 2012) are conducted annually across cities and age groups. The National Talent Search Examination (NTSE)vii was intended only for the Science students but in 1976 students from the Social sciences, Engineering and Medicine were included (Kurup et al., 2013). The Indian Government envisioned the National Policy of Education (NPE), 1986 which was concerned with providing quality education for all, with special focus on the disadvantaged groups in 
the country. The NPE instituted the Jawahar Navodaya Vidyalayas (JNV), a residential school in rural areas to minimise the ruralurban disparities by promoting quality education. The main intention of the JNVs was to recognise and capture the best of rural talent and which served as a unique experiment in gifted education as well (National Policy of Education, 1986). The objective of the programme is to encourage excellence in education among the underprivileged by instiling moral values and justice. JNVs follow the Central Board of Secondary Education (CBSE) curriculum, which includes general studies, work experience, physical education, mathematics, physics, chemistry, biology, biotechnology, economics, political science and so forth. However, there are constraints in continuing these programmes due to insufficient funds and irregular allocation of resources (Wright, 2008). Another programme called INSPIREviii which stands for Innovation in Science Pursuit for Inspired Research. The main objective of this programme is to stimulate the creative curiosity of talented students in the natural sciences at a nascent age (Kurup et al., 2013). An initiative was started by the National Institute of Advanced Studies (NIAS) through the NIAS Gifted Children's

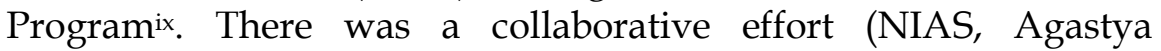
Foundation and the University of Delhi) in India to understand and promote the concept of giftedness especially in the domains of Mathematics and Science (Kurup et al., 2013).

Along with enumerating gifted programmes, it would not seem irrelevant to mention a school especially for gifted children. Jyana Prabodhini School was set up in 1962 in Pune to foster gifted abilities in children that are the valuable assets of a nation (Jyana Prabodhini Prashala, n.d). The entrance examination comprises of a series of psychological tests and several group interviews. The curriculum in the school for gifted children is framed on the lines of psychologist J.P Guildford's Structure of Intellect Modelx (Kurup et al., 2013) and Accelerated learning programmes are offered in Mathematics and English (Naik, n.d).

Tracing all these programmes of giftedness and talent, the emphasis on maths and science comes across clearly. This can be interpreted as a reflection of what is societally valued as 'gifted', despite several other cultural interpretations of giftedness 
(Stevenson, n.d) and reflects the predominant trend of what shapes educational policies, discourses, and practices of giftedness. Moreover, a cursory review of giftedness models and Indian programmes shows the interest and resources invested in the field.

Another important dimension that my doctoral work highlights is that even as characteristics of giftedness, identification mechanisms and assessment criteria have been thought through, the child "who is being assessed" seems peripheral to the process. As a result, the personhood of the child despite his/her abilities has largely been discounted.

\section{Bridging the gap: Exploring questions, emergent dilemmas}

As part of my doctoral research, therefore, I sought to understand the psychosocial experiences of children identified as gifted. In order to do so, I selected a few children identified as gifted by the NIAS Gifted Children Program. Over the period of one year, I have followed these "gifted children" into their homes, schools and enrichment spaces. The three diverse schooling environments were chosen as they claimed to understand and facilitate the needs of the gifted child. I have interacted with families, teachers, peers, and professionals in gifted education, in order to understand the child and the larger social world within which she/he is embedded.

Through the course of the doctoral fieldwork, I have observed how parents were strategising to expose their children to exclusive environments and practicing 'concerted cultivation' (Lareau, 2003, p. 1) by involving their child in organised activities to nurture their talents and abilities. There were several stimulating environments being created in and outside of diverse schooling spaces to foster giftedness in the child. Preliminary observations of the field suggest that a certain social classes seem to be constructing the ability of a child and this project of giftedness seems to extend beyond the child to shape larger educational structures, discourses and practices.

While I began my fieldwork with the intention of trying to understand psychological experiences and how these interact with the social world of the child, the evolving nature of the field led me to then engage with the social phenomena of giftedness itself. Currently in my study, I am attempting to understand how 
giftedness circulates in the social environment, the factors that produce it and the practices that enable and sustain it in the child and the larger environment.

Several questions have arisen as a consequence of investigating the social processes of giftedness. I would like to highlight some of them here. What kinds of abilities and skills were valued in formal schools? ${ }^{x i}$ Can the culture of an institution dictate what abilities and skills are recognised or worth recognising? If so, are individual abilities that gain importance socially and culturally determined?

If one assumes that the social is the only edifice on which any ability, talent or gift can exist, then one needs to investigate, what are the processes by which these abilities or talents get produced in the social space? What are the parental practices and the thrust that schooling structures give towards creating a culture that fosters giftedness in the child and why?

While all the above questions seem valid and have largely emerged from my engagement with the field, it is equally relevant to mention the challenges and struggles of parents, teachers and children while they are part of the process that creates the project of giftedness. Parents of children marked as gifted feel a lack of support from institutions and have little or no recourse apart from schooling systems. It is a few privileged parents who opt for alternative modes of education such as home schooling their child to salvage the 'gift', which would otherwise be lost or forgotten in regular schooling. There have also been desperate pleas for help from parents who want advice and direction on how to occupy their child's intellectual curiosity, which seems to be abundant but a dearth of avenues to invest and harness this curious energy. Due to this gap, their children are becoming depressed or hyperactive and clinical interventions do not seem to serve the purpose as they push the child deeper into the crevasses of despair. Within schooling systems, teachers are unable to contain the giftedness of the child within the constraints of a limited learning environment. Most often, the school management is not able to justify the investment of huge resources to serve the needs of a few children as compared to the majority of children seeking educational facilities. 
Even though my study mostly focusses on the social construction of giftedness (Borland, 1997) it would not be justifiable to overlook the practical difficulties and challenges that form pressing concerns of parents, teachers and the child. Intending to take into account these narratives, I am currently grappling with how children identified as gifted and their guardians look for direction from professionals and practitioners in the field of gifted education, while at the same time I am trying to unpack the social practices followed by professionals and other social actors who are producing excellence in the child through the project of giftedness. Through this study I hope to contribute to the sociology of education in terms of understanding middle class/ elite aspirations with regard to education of their children, elite parenting practices, conceptions of giftedness and how cultural capital (Bourdieu, n.d., as cited in Richardson, J., 1986) is transmitted from one generation to the next.

\section{References}

Borland, J. H. (1997). The construct of giftedness. Peabody Journal of Education, 72(3/4), 6-20.

Bourdieu, P. (1986). The forms of capital. In J. Richardson (Ed.) Handbook of Theory and Research for the Sociology of Education. New York: Greenwood.

Callahan, C.M. (1997). The construct of talent. Peabody Journal of Education, $72(3 / 4), 21-35$.

Gardner, H. (2006). Multiple intelligences: New horizons (Completely rev. and updated.). New York: Basic Books.

Jagadis Bose National Science Talent Search. (2010). Retrieved from http://www.jbnsts.org/jbweb/mission.htm

Jnana Prabodhini Prashala. (n.d). Retrived from http:// prashala.jnanaprabodhini.org/

Kurup, A., \& Maithreyi, R. (2012). A review of challenges in developing a national program for gifted children in India's diverse context. Roeper Review, 34(4), 215-223. DOI: 10.1080/02783193.2012.715332

Kurup, A., Basu, A., Chandra, A., Jayan, P., Nayar, S., Jain, G. C., \& Rao, A. G. (2013). An introduction: Reading on giftedness in children. National Institute of Advanced Studies, Indian Institute of Science Campus, Bangalore.

Lareau, A. (2003). Unequal childhoods: Class, race, and family life. Berkeley: University of California Press. 
Lefton, L. A. (1997). Why I teach the way I do: Repackaging psychology. In R. J. Sternberg (Ed.)., Teaching introductory psychology: Survival tips from the experts. Washington, DC: American Psychological Association.

Miller, A. L. (2012). Conceptualisations of creativity: Comparing theories and models of giftedness. Roeper Review, 34(2), 94-103.

Naik, M. (n.d). Does accelerated learning work? For which students? Jnana Prabodhini, Pune, Maharashtra. Retrieved from http:// prashala.jnanaprabodhini.org

National Policy on Education. (1986). Retrieved on July 11, 2015, from Ministry of Human Resource Department, Department of Education.

Renzulli, J. S. (1978). What makes giftedness? Re-examining a definition. The Phi Delta Kappan, 60(3), 180-184.

Silverman, L. K. (1997). The construct of asynchronous development. Peabody Journal of Education, 72(3/4), 36-58.

Sternberg, R. (2013 [1997]). Contemporary theories of intelligence. In W. Reynolds, \& J.G. Miller (Eds.), Handbook of psychology: Vol 7 Educational Psychology (pp. 23-46). New Jersey: John Wiley \& Sons Inc.

Stevenson, H. W. (n.d.). Cultural interpretations of giftedness: The case of East Asia. Talent in context: Historical and social perspectives on giftedness, 61-77. doi:10.1037/10297-004

The Times of India. (2014). A giant leap for 'gifted education' in Kolkata, Retrieved from http://timesofindia.indiatimes.com/city/kolkata/Agiant-leap-for-gifted-education-in-Kolkata/articleshow/29570962.cms

Worrell, F.C., Subotnik, R. F., \& Olszewski-Kubilius, P. (2011). Rethinking giftedness and gifted education: A proposed direction forward based on psychological science. American Psychological Association, Sage Publication, 12(1), 3-54.

Wright, B. J. (2008). A global conceptualisation of giftedness: A comparison of US and Indian Gifted Education programs. Dominican University of California, San Rafael, CA.

i Paul Witty argued that there are children whose outstanding potentialities in various domains can be recognised largely by their performance (Renzulli, 1978).

ii Joseph Renzulli said that the three factors that are interconnected in understanding giftedness, i.e., above average ability, creativity and task commitment, in varying proportions produce gifted behaviour. The definition broadened the understanding of the term giftedness from the earlier notion of innate intellectual ability to shape and influence the 
psychosocial variables that could manifest in gifted behaviour in children (Worrell et al., 2011).

iii Gardner suggested that there are seven different intelligences (linguistic, musical, logical-mathematical, spatial, bodily-kinaesthetic, interpersonal, and intrapersonal) and an individual can be gifted in more than one of the mentioned domain of activities (Miller, 2012).

iv Robert Sternberg defined giftedness as the ability to adapt, to shape, and select environments to accomplish one's goals and those of one's society and culture. The focus of the definition is not only on scholastic intelligence, but also on developing skills which are adaptable to novel settings and takes into account, the tendency to select or shape environments that lead to the enhancement of one's skill sets (Miller, 2012).

v The Columbus Group related giftedness with the concept of asynchronous development as they sought to define it as - advanced cognitive abilities and heightened intensity combine to create inner experiences and awareness that are qualitatively different from the norm. The uniqueness of the gifted renders them particularly vulnerable and requires modifications in parenting, teaching and counselling in order for them to develop optimally. Thus, cognitive science as an important component was introduced into giftedness studies (Silverman, 1997).

vi It was instituted by the Government of West Bengal in 1958. The mission of this program was to identify and encourage talented students in the sciences and mathematics (Jagadis Bose National Science Talent Search, 2010).

vii This Program was started by the National Council for Education Research and Training (NCERT). The assessment of students is done by a written test, evaluation of the students' project report and an interview. In the revised form, scholarships are awarded on the basis of a students' performance on two tests: the Mental Abilities Test, Scholastic Aptitude Test and an interview.

viii This program was implemented in 2008 by the Department of Science and Technology, Government in India. The unique feature of this program is that it does not conduct any competitive exams and relies on the current central curriculum for the identification of talent. Therefore, children who excel in the class $X$ and college exams can avail of the scholarships and other resources that this program has to offer.

ix This program was implemented in India to identify children who have extraordinary abilities or skills within education systems and campaign for equal learning opportunities for them (Kurup et al., 2013). Office of the Principle Scientific Advisor (PSA) to Government of India under the 
leadership of Prof R. Chidambaram commissioned India's first national project on gifted education: The Identification of Gifted Children, Age 3-15 years (with a Special Focus on Mathematics and Science) to the National Institute of Advanced Studies in 2010.

x The Guilford's structure of intellect model consists of 3 dimensions, which are 5 contents, 6 products and 6 operations giving rise to 150 factors of intellectual ability. According to Guilford, intelligence is a complex phenomenon. (Lefton, 1997)

xi As part of the methodology of my ethnographic study, I followed children, identified as gifted by the NIAS Gifted Children's Project assessment protocol, into diverse schooling environments in which they were placed. A few children that I followed were studying in an international school. 